\title{
High Affinity Pharmacological Profiling of Dual Inhibitors Targeting RET and VEGFR2 in Inhibition of Kinase and Angiogeneis Events in Medullary Thyroid Carcinoma
}

\author{
Nageswara Rao Dunna ${ }^{1}$, Venkatesh Kandula ${ }^{2}$, Amandeep Girdhar ${ }^{5}$,Amareshwari \\ Pudutha $^{2}$, Tajamul Hussain ${ }^{3}$, Srinivas Bandaru ${ }^{4}$, Anuraj Nayarisseri ${ }^{5 *}$
}

\begin{abstract}
Clinical evidence shows that dual inhibition of kinases as well angiogenesis provides ideal therapeutic option in the treatment of medullary thyroid carcinoma (MTC) than inhibiting either of these with the events separately. Although treatment with dual inhibitors has shown good clinical responses in patients with MTC, it has been associated with serious side effects. Some inhibitors are active agents for both angiogenesis or kinase activity. Owing to narrow therapeutic window of established inhibitors, the present study aims to identify high affinity dual inhibitors targeting RET and VEGFR2 respectively for kinase and angiogenesis activity. Established inhibitors like Vandetanib, Cabozantinib, Motesanib, PP121, RAF265 and Sunitinib served as query parent compounds for identification of structurally similar compounds by Tanimoto-based similarity searching with a threshold of $95 \%$ against the PubChem database. All the parent inhibitors and respective similar compounds were docked against RET and VEGFR2 in order to retrieve high affinity compounds with these two proteins. AGN-PC-0CUK9P PubCID: 59320403 a compound related to PPI21 showed almost equal affinity for RET and VEGFR2 and unlike other screened compounds with no apparent bias for either of the receptors. Further, AGNPC-0CUK9P demonstrated appreciable interaction with both RET and VEGFR2 and superior kinase activity in addition to showed optimal ADMET properties and pharmacophore features. From our in silico investigation we suggest AGN-PC-0CUK9P as a superior dual inhibitor targeting RET and VEGFR2 with high efficacy which should be proposed for pharmacodynamic and pharmacokinetic studies for improved treatment of MTC.
\end{abstract}

Keywords: Medullary thyroid carcinoma - RET - VEGFR2 - dual inhibitors - virtual screening

Asian Pac J Cancer Prev, 16 (16), 7089-7095

\section{Introduction}

Medullary thyroid carcinoma (MTC) is one of the rare forms of malignancy which accounts for 3-10\% of all thyroid carcinomas (Kilfoy et al., 2009; DeSantis et al., 2014). MTCs arise from the parafollicular cells or C cells of the thyroid gland which is responsible for up to $13.4 \%$ of all deaths related to this disease. (Hundahl et al., 1991; Marsh et al., 1995; Gilliland et al., 1997). Although at the early stages of the cancer proved to be cured by primary surgery in vast majority of patients however, there exists a fair chance that disease can persist or recur with detrimental effects (Rougier et al., 1983; Samaan et al., 1988; Brierley et al., 1996). Local and distant metastases has been well associated with increasing mortality and clinical procedures like reoperation and perhaps radiotherapy can improve the outcome for some patients, but nevertheless, there is a need for novel treatments for better outcome. Till date, no comprehensive clinical trial data are available on conventional cytotoxic agents for the treatment of MTC (Schlumberger et al., 2008; Masbi et al., 2014).

Emerging body of evidence proves that patients with distant metastases, in particular, might benefit from several novel compounds directed against angiogenesis and kinase activity and therefore RET and VEGF receptors forms an ideal drug targets respectively inhibiting the kinase activity and angiogenic events observed in MTC. In fact kinase inhibition and antiangiogenic therapy should form a treatment rational for MTC because increased expression of hypoxia-inducible transcription factor promotes increased expression of vascular endothelial growth factor (VEGF) and tumor angiogenesis and RET inhibition has been correlated with VEGF downregulation. (Bunone et

${ }^{1}$ School of Chemical and Biotechnology, SASTRA University, Thanjavur, India, ${ }^{2}$ Department of Genetics and Biotechnology, Osmania University, Hyderabad, Telangana, ${ }^{4}$ Genetics and Hospital for Genetic Diseases, Osmania University, Begumpet, Hyderabad, ${ }^{5}$ In silico Research Laboratory, Eminent Biosciences, Vijaynagar, Indore, India, ${ }^{3}$ Center of Excellence in Biotechnology Research, College of Science, King Saud University, Riyadh, Saudi Arabia*For correspondence: anuraj@eminentbio.com 
al., 1999; Petrangolini et al., 2006). In addition to RET, EGFR was reported to be expressed in large number of MTC samples (Mitsiades et al., 2006). Some competitive inhibitors of ATP binding have been reported to exert an inhibitory effect on the kinase activity of RET (Santoro et al., 2006) in addition, multikinase inhibitors share the ability of inhibiting VEGFRs, therefore attacking endothelial cells besides cancer cells expressing RET (Yeganeh et al., 2015). These compounds might therefore have a combined effect inhibiting RET in tumor cells and VEGFR in endothelial cells.

Although, RET and VEGFR dual inhibitors have been clinically successful nevertheless, In to in a considerable proportion MTC patients with regular dosing regimen of these drugs showed toxic effects like fatigue, hypertension, nausea, diarrhoea and abdominal discomfort, mucositis, skin rashes and acne (Schlumberger et al., 2008). Therefore in the view of given observation, the present study is sought to identify a high affinity dual inhibitor targeting RET and VEGFR bestowed with better ADMET profiles, low toxicity, activity and appreciable and pharmacophoric profiles.

\section{Materials and Methods}

\section{Selection of potent RET and VEGFR2 inhibitors}

Number of parent inhibitor their PubChem ID selected for molecular docking is listed in Table1

\section{Preparation of protein and compounds}

Structures of RET (PDB ID: 2IVV) (Knowles et al., 2006) and VEGFR (PDB ID: 3V2A) (Brozzo et al., 2012) were retived from Protein Data Bank (PDB). The proteins prepared using the PrepWiz module of Schrodinger suite. In the preparation procedure, the protein was first preprocessed by assigning the bond bonders and hydrogen, creating zero order bonds to metals and adding disulphide bonds. The missing side chains and loops were filled using Prime Module of Schrodinger. Further all the water molecules were deleted beyond $5 \AA$ from hetero groups. Once the protein retrieved was preprocessed, $\mathrm{H}$ bonds were assigned which was followed by energy minimization by OPLS 2005 force field. The final structure obtained was saved in pdb format for further studies. All the ligands were optimized through OPLS 2005 force field algorithm (Jorgensen et al., 1996) embedded in the LigPrep module of Schrodinger suite, 2013 (Schrodinger. LLC, New York, NY). The ionizations of the ligand were desalted and retained at the original state. The structures thus optimized were saved in sdf format for docking procedures.

\section{Structure similarity search}

The selected parent inhibitors served as query molecule in pursuit to identify still better druglike compound than the parent compound. Similarity search was supervised by Binary Finger Print Based Tanimoto similarity equation to retrieve compounds with similarity threshold of $95 \%$ against NCBI's Pubchem compound database (Bandaru et al., 2014).

\section{Molecular docking of compounds}

Molecular docking program- Molegro Virtual Docker (MVD) which incorporates highly efficient PLP (Piece wise Linear potential) and MolDock scoring function provided a flexible docking platform (Thomsen et al.2006, Bandaru et al., 2015). All the ligands were docked at the inhibitory site of RET and VEGFR2. Docking parameters were set to $0.20 \AA$ as grid resolution, maximum iteration of 1500 and maximum population size of 50. Energy minimization and hydrogen bonds were optimized after the docking. Simplex evolution was set at maximum steps of 300 with neighborhood distance factor of 1 (Kelotra et al., 2014). Binding affinity and interactions of ligands with protein were evaluated on the basis of the external and internal ES (Electrostatic Interaction), hydrogen bond interactions and sp2-sp2 torsions. Energy of the post docked ligand-receptor complex was minimized using Nelder Mead Simplex Minimization (using non-grid force field and $\mathrm{H}$ bond directionality) (Nelder and Mead, 1965]. On the basis of affinity (otherwise called rerank score) best interacting compound was selected from against both RET and VEGFR2.

Bioactivity and ADMET profiling of compounds.

All the compounds were screened for its drug ability by lipinksi filters. Biological activity of the ligands was predicted using Molinspiration webserver

Table 1. Number of Similar Compounds Retrieved through Structure based Similarity Search Against Parent Compounds. The Similar Compounds Docked Compound Against RET and VEGFR2 and Compounds with high Affinity Against RET and VEGFR2 is Listed

\begin{tabular}{ccccc}
\hline S.No & Parent Inhibitors & $\begin{array}{c}\text { Number of similar compounds } \\
\text { obtained with 95\% similarity }\end{array}$ & $\begin{array}{c}\text { Best docked similar } \\
\text { compound against RET }\end{array}$ & $\begin{array}{c}\text { Best docked similar compound } \\
\text { against VEGFR2 }\end{array}$ \\
\hline 1 & Vandetanib & 51 & $\begin{array}{c}\text { SCHEMBL15445277 } \\
\text { (PubCID: 89946989) }\end{array}$ & $\begin{array}{c}\text { FT-0665754 } \\
\text { (PubCID: 71776861) } \\
\text { AGN-PC-0BWTZX } \\
\text { (PubCID: 57810063) } \\
\text { AGN-PC-0BWU2Y } \\
\text { (PubCID: 57810172) }\end{array}$ \\
3 & Cabozantinib & 192 & $\begin{array}{c}\text { SCHEMBL16007556 } \\
\text { (PubCID: 90386511) }\end{array}$ & $\begin{array}{c}\text { AGN-PubCID: 69720818) } \\
\text { AGN-PC-0CUK9P }\end{array}$ \\
4 & Motesanib & 40 & AGN-PC-0CUK9P & (PubCID: 59320403) \\
(PubCID: 59320403) \\
5
\end{tabular}


Dual Inhibitors Targeting RET and VEGFR2 for Inhibition of Kinase and Angiogenesis in Medullary Thyroid Carcinoma Table 2. Affinity (Rerank scores) of Parents and Best Docked Compounds Against RET and VEGFR2

\begin{tabular}{|c|c|c|c|}
\hline Parent compound & $\begin{array}{c}\text { Best docked } \\
\text { similar compound }\end{array}$ & $\begin{array}{c}\text { RERANK } \\
\text { AGAINST RET }\end{array}$ & $\begin{array}{c}\text { RERANK } \\
\text { AGAINST VEGFR2 }\end{array}$ \\
\hline \multirow[t]{3}{*}{ Vandetanib } & & -106.753 & -81.6459 \\
\hline & SCHEMBL15445277 (PubCID: 89946989) & -113.487 & -76.4717 \\
\hline & FT-0665754 (PubCID: 71776861$)$ & -88.3915 & -114.706 \\
\hline \multirow[t]{3}{*}{ Cabozantinib } & & -107.785 & -72.395 \\
\hline & AGN-PC-0BWU2Y (PubCID: 57810172) & -126.331 & -125.015 \\
\hline & AGN-PC-0BWTZX (PubCID: 57810063) & -86.281 & -157.168 \\
\hline \multirow[t]{3}{*}{ Motesanib } & & -102.451 & -101.438 \\
\hline & SCHEMBL16007556 (PubCID: 90386511) & -111.254 & -84.212 \\
\hline & AGN-PC-0IGM5P (PubCID: 69720818) & -98.541 & -88.910 \\
\hline \multirow[t]{2}{*}{ PP121 } & & -132.017 & -110.027 \\
\hline & AGN-PC-0CUK9P (PubCID: 59320403) & -128.326 & -126.420 \\
\hline \multirow[t]{3}{*}{ RAF265 } & & -104.352 & -71.63 \\
\hline & SCHEMBL2447316 (PubCID: 87389359) & -100.546 & -101.596 \\
\hline & AGN-PC-00SCHG (PubCID: 16064893) & -103.750 & -72.684 \\
\hline \multirow[t]{3}{*}{ Sunitinib } & & -97.231 & -80.980 \\
\hline & PubCID: 91384940 & -92.595 & -76.250 \\
\hline & PubCID: 91066128 & -96.452 & -78.210 \\
\hline
\end{tabular}

( ${ }^{\circ}$ Molinspiration Cheminformatics 2014). The complete ADMET properties was calculated using admetSAR (Cheng et al., 2012). Toxicity of the compounds was predicted using LAZAR toxicity prediction program (Maunz et al., 2013).

\section{Results and Discussion}

Number of similar compounds screened with $\geq 95$ similarity corresponding to each parent compound and their best docked similar compounds against RET and VEGFR is show in Table 1.

As evident from affinity (rerank) score, amongst all the parent inhibitors PP121 showed highest and optimal affinity against RET and VEGFR2 (Table 2). According to docking analysis it is quite apparent that the parent compounds show good and optimal affinity to either RET or VEGFR2 receptor but not both, therefore our pursuit was to identify high affinity compound promiscuously targeting RET and VEGFR2 with almost similar affinity. The similar compounds thus retrieved against parent after virtual screenings were docked separately to RET as well as VEGFR2. The similar compounds that showed highest affinity for RET however did not show high affinity against VEGFR and vice versa. In such case two compounds were retrieved for each parent, one showing high affinity against RET and the other against VEGFR2. For example, compound SCHEMBL15445277 (PubCid: 89946989) similar to Vandetanib, though had high affinity against RET (-113.487) than its parent compound but the affinity for VEGFR2 (-76.4717) was quite declined. While, compound FT-0665754 (PubCid:7177686) which is again a similar compound to Vandetanib, had higher affinity to VEGFR2 than its parent compound however, affinity was considerably low against RET. A similar trend can be observed with AGN-PC-0BWTZX (PubCid: 57810063) a similar compound to Cabozantinib, which shows superior affinity against VEGFR2 (-157.168) but not against RET, at the similar note, compound SCHEMBL16007556 (PubCid: 90386511) akin to Motesanib although has high affinity against RET (-111.254) but declined affinity against VEGFR2 (-84.212). In overall it can therefore be interpreted that such compounds may form a good inhibitors to either RET or VEGFR2 but not both and do not form a potential dual inhibitors. In further docking analysis, we found that similar compounds showed even declined binding affinity than its parent compound. For example, compounds with PubCid: 91384940 and 91066128 both showed decreased binding affinity against RET and VEGFR than its parent compound Sunitinib. Therefore, such compounds can neither form potential dual inhibitor nor can form potential inhibitor either to RET or VEGFR.

Through extensive affinity analysis we found that AGN-PC-0CUK9P (PubCid: 59320403)akin to PP121 to show optimal binding affinity against both RET and VEGFR. It can be further noted that AGN-PC-0CUK9P though does not have high affinity against RET as its parent compound PP121, nevertheless, it can be thought to be the be the better potentiator of both RET and VEGFR because its parent compound PP121 has reduced affinity against VEGFR but affinity of AGN-PC-0CUK9P is almost similar in both RET and VEGFR. Similarly unlike similar compounds as afore mentioned which have a disproportionate affinity against RET and VEGFR, AGNPC-0CUK9P shows almost equal affinity to these two receptors. In addition it's quite worthy to note that, AGNPC-0CUK9P was the only compound retrieved against its parent to have highest and almost equivalent binding affinity to both RET and VEGFR2. Interestingly, AGNPC-0CUK9P, shows highest affinity against RET than similar compounds retrieved against respective parents furthermore, among the similar compounds, its affinity against VEGFR2 is immediately second to Cabozantinib similar -AGN-PC-0BWTZX (-157.168) (since as earlier mentioned though AGN-PC-0BWTZX has highest affinity against VEGFR2 however, shows declined affinity against RET which makes it a suboptimal dual inhibitor).

The superior affinity of compound AGN-PC-0CUK9P can be attributed to its excellent interaction profile 
Nageswara Rao Dunna et al

especially in terms of electrostatic and H-bonding interactions. Apparent from the docking profile of compound energy values (Table 3 ) the descriptors of external ligand interactions contributes higher stability than internal ligand interactions. Further external ligand interactions were stabilized mostly by steric energy guided by piece wise linear potentials. While in internal ligand interactions, the torsional strain contributes for the stability of the ligand receptor interactions. Owing to the promiscuous and almost equivalent affinity characteristics against RET and VEGFR, AGN-PC-0CUK9P can be thought to be optimal potentiator of RET and VEGFR

Table 3. Ligand- Receptor Interaction Energy Overview of AGN-PC-0CUK9P (PubCID: 59320403) Against RET and VEGFR2

\begin{tabular}{lcc}
\hline & \multicolumn{2}{c}{ Affinity } \\
& RET & VEGres against \\
& \multicolumn{2}{c}{ Rerank Score } \\
\hline Total Energy & -128.326 & -126.42 \\
External Ligand interactions & -155.213 & -154.521 \\
Protein - Ligand interactions & -155.213 & -154.521 \\
Steric (by PLP) & -122.09 & -139.316 \\
Steric (by LJ12-6) & -28.393 & -12.178 \\
Hydrogen bonds & -4.73 & -3.027 \\
Hydrogen bonds (no directionality) & 0 & 0 \\
Electrostatic (short range) & 0 & 0 \\
Electrostatic (long range) & 0 & 0 \\
Internal Ligand interactions & 26.887 & 28.101 \\
Torsional strain & 4.395 & 4.397 \\
Torsional strain (sp2-sp2) & 0 & 0 \\
Hydrogen bonds & 0 & 0 \\
Steric (by PLP) & 4.014 & 5.987 \\
Steric (by LJ12-6) & 18.478 & 17.717 \\
Electrostatic & 0 & 0 \\
\hline
\end{tabular}

than any other compounds analyzed hitherto.

Further, we tested for activity against different drug targets (Table 4), above all, it was AGN-PC-0CUK9P which demonstrated highest kinase activity and least activity against other drug targets (demonstrating it to be target specific), which in addition testifies it to be the better potentiator of both RET and VEGFR2 .

Owing to better interaction profiles and activity, the toxicity testing still mandates a compound to be a bonafide drug. Therefore in the view we tested the carcinogenic as well as mutation profiles of the screened compound (Table 5). Out of screened compounds FT-0665754 a compound akin to Vandetinib was shown to be mutagenic in while, Motesanib similar SCHEMBL16007556 and Sunitinib similar (PubCID: 91384940) both showed a carcinogenic profiles, while others proved to be non-toxic and demonstrate safety profiles. Further, it can be noted that, along with good affinity profile and appreciable kinase activity, AGN-PC-0CUK9P was neither carcinogenic nor mutagenic therefore qualifying

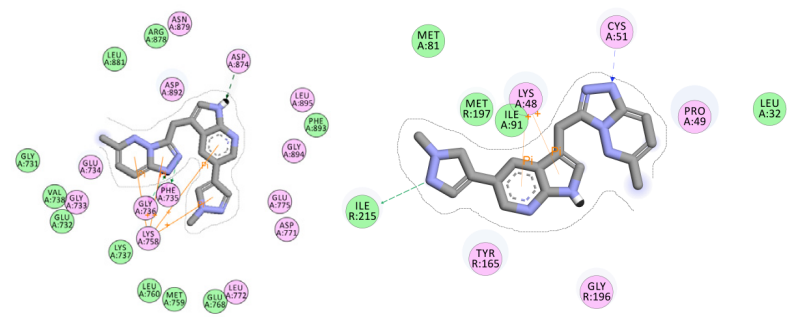

Figure 1.AGN-PC-0CUK9P interacting the active site of RET (left) and in the active site of VEGFR2 (right). Residues circled in green participate in vander waals interaction while residues in pink forms electrostatic interactions. Hydrogen bonds are shown as green (donor) and blue (acceptor) arrows

Table 4. Bioactivity Prediction of Parent and Similar Compounds Against Various Drug Targets

\begin{tabular}{|c|c|c|c|c|c|c|}
\hline & GPCR ligand & $\begin{array}{l}\text { Ion channel } \\
\text { modulator }\end{array}$ & $\begin{array}{l}\text { Kinase } \\
\text { inhibitor }\end{array}$ & $\begin{array}{l}\text { Nuclear } \\
\text { receptor ligand }\end{array}$ & $\begin{array}{l}\text { Protease } \\
\text { inhibitor }\end{array}$ & $\begin{array}{l}\text { Enzyme } \\
\text { inhibitor }\end{array}$ \\
\hline Vandetanib & 0.05 & -0.12 & 0.64 & -0.45 & -0.29 & 0.04 \\
\hline SCHEMBL15445277 & & & & & & \\
\hline $\begin{array}{l}\text { (PubCID: } 89946989) \\
\text { FT-0665754 }\end{array}$ & 0.13 & -0.11 & 0.61 & -0.4 & -0.28 & 0.02 \\
\hline (PubCID: 71776861) & 0.11 & -0.05 & 0.7 & -0.36 & -0.26 & 0.12 \\
\hline Cabozantinib & 0.06 & -0.1 & 0.43 & -0.01 & 0.07 & 0.05 \\
\hline $\begin{array}{l}\text { AGN-PC-0BWU2Y } \\
\text { (PubCID: 57810172) }\end{array}$ & 0.05 & -0.46 & 0.15 & -0.3 & 0.12 & -0.15 \\
\hline $\begin{array}{l}\text { AGN-PC-0BWTZX } \\
\text { (PubCID. 57810063) }\end{array}$ & & & & & & \\
\hline & -0.06 & -0.66 & 0.09 & -0.5 & 0.04 & $\begin{array}{r}-0.33 \\
0.06\end{array}$ \\
\hline $\begin{array}{l}\text { Motesanib } \\
\text { SCHEMBL16007556 }\end{array}$ & 0.21 & -0.08 & 0.47 & -0.02 & 0.07 & 0.06 \\
\hline $\begin{array}{l}\text { (PubCID: 90386511) } \\
\text { AGN-PC-0IGM5P }\end{array}$ & 0.2 & -0.18 & 0.2 & -0.37 & 0.11 & -0.1 \\
\hline (PubCID: 69720818) & 0.32 & -0.22 & 0.26 & -0.26 & 0.15 & -0.09 \\
\hline PP121 & 0.39 & 0.09 & 1.43 & -0.71 & -0.11 & 0.76 \\
\hline $\begin{array}{l}\text { AGN-PC-0CUK9P } \\
\text { (PubCID: 59320403) }\end{array}$ & 0.26 & 0.38 & 3.45 & -0.96 & -0.25 & 0.18 \\
\hline RAF265 & 0.47 & 0.11 & 0.84 & -0.19 & 0.23 & 0.43 \\
\hline SCHEMBL2447316 & & & & & & \\
\hline (PubCID: 87389359) & 0.46 & 0.05 & 1 & -0.32 & 0.23 & 0.42 \\
\hline AGN-PC-00SCHG (PubCID: 16064893) & 0.43 & 0.09 & 0.88 & -0.29 & 0.14 & 0.33 \\
\hline Sunitinib & -0.16 & -0.62 & 0.51 & -0.8 & -0.51 & -0.23 \\
\hline PubCID: 91384940 & -0.03 & -0.45 & 0.43 & -0.71 & -0.17 & -0.13 \\
\hline PubCID: 91066128 & -0.1 & -0.31 & 0.39 & -0.58 & -0.23 & -0.03 \\
\hline
\end{tabular}


Dual Inhibitors Targeting RET and VEGFR2 for Inhibition of Kinase and Angiogenesis in Medullary Thyroid Carcinoma Table 5. Toxicity Prediction of Virtually Screened Compounds by LAZAR server in Different Cell Lines

\begin{tabular}{|c|c|c|c|c|c|c|}
\hline & & $\begin{array}{l}\text { DSSTox } \\
\text { Carcinogenic } \\
\text { Potency DBS } \\
\text { MultiCellCall }\end{array}$ & $\begin{array}{l}\text { DSSTox } \\
\text { Carcinogenic } \\
\text { Potency DBS } \\
\text { Mutagenicity }\end{array}$ & $\begin{array}{c}\text { DSSTox } \\
\text { Carcinogenic } \\
\text { Potency DBS } \\
\text { Rat }\end{array}$ & $\begin{array}{c}\text { DSSTox } \\
\text { Carcinogenic } \\
\text { Potency DBS } \\
\text { Hamster }\end{array}$ & $\begin{array}{c}\text { DSSTox } \\
\text { Carcinogenic } \\
\text { Potency DBS } \\
\text { Mouse }\end{array}$ \\
\hline \multirow{2}{*}{$\begin{array}{l}\text { Vandetanib } \\
\text { Similars }\end{array}$} & $\begin{array}{l}\text { SCHEMBL15445277 } \\
\text { (PubCID: 89946989) }\end{array}$ & non-carcinogen & non- mutagenic & $\begin{array}{l}\text { non- } \\
\text { carcinogen }\end{array}$ & $\begin{array}{c}\text { non- } \\
\text { carcinogen }\end{array}$ & non-carcinogen \\
\hline & $\begin{array}{c}\text { FT-0665754 } \\
\text { (PubCID: } 71776861 \text { ) }\end{array}$ & non-carcinogen & mutagenic & $\begin{array}{l}\text { non- } \\
\text { carcinogen }\end{array}$ & $\begin{array}{c}\text { non- } \\
\text { carcinogen }\end{array}$ & non-carcinogen \\
\hline \multirow{2}{*}{$\begin{array}{l}\text { Cabozantinib } \\
\text { Similars }\end{array}$} & $\begin{array}{l}\text { AGN-PC-0BWU2Y } \\
\text { (PubCID: 57810172) }\end{array}$ & non-carcinogen & non- mutagenic & $\begin{array}{l}\text { non- } \\
\text { carcinogen }\end{array}$ & $\begin{array}{l}\text { non- } \\
\text { carcinogen }\end{array}$ & non-carcinogen \\
\hline & $\begin{array}{l}\text { AGN-PC-0BWTZX } \\
\text { (PubCID: 57810063) }\end{array}$ & non-carcinogen & non- mutagenic & $\begin{array}{l}\text { non- } \\
\text { carcinogen }\end{array}$ & $\begin{array}{l}\text { non- } \\
\text { carcinogen }\end{array}$ & non-carcinogen \\
\hline \multirow{2}{*}{$\begin{array}{l}\text { Motesanib } \\
\text { Similar }\end{array}$} & $\begin{array}{c}\text { SCHEMBL16007556 } \\
\text { (PubCID: 90386511) }\end{array}$ & non-carcinogen & non- mutagenic & $\begin{array}{c}\text { non- } \\
\text { carcinogen }\end{array}$ & carcinogen & non-carcinogen \\
\hline & $\begin{array}{c}\text { AGN-PC-0IGM5P } \\
\text { (PubCID: 69720818) }\end{array}$ & non-carcinogen & non- mutagenic & $\begin{array}{c}\text { non- } \\
\text { carcinogen }\end{array}$ & $\begin{array}{l}\text { non- } \\
\text { carcinogen }\end{array}$ & non-carcinogen \\
\hline $\begin{array}{l}\text { PP121 Similar } \\
\mathrm{s}\end{array}$ & $\begin{array}{l}\text { AGN-PC-0CUK9P } \\
\text { (PubCID: 59320403) }\end{array}$ & non-carcinogen & non- mutagenic & $\begin{array}{c}\text { non- } \\
\text { carcinogen }\end{array}$ & $\begin{array}{c}\text { non- } \\
\text { carcinogen }\end{array}$ & non-carcinogen \\
\hline \multirow{2}{*}{$\begin{array}{l}\text { RAF265 } \\
\text { Similars }\end{array}$} & $\begin{array}{l}\text { SCHEMBL2447316 } \\
\text { (PubCID: } 87389359 \text { ) }\end{array}$ & non-carcinogen & non- mutagenic & $\begin{array}{l}\text { non- } \\
\text { carcinogen }\end{array}$ & $\begin{array}{c}\text { non- } \\
\text { carcinogen }\end{array}$ & non-carcinogen \\
\hline & $\begin{array}{l}\text { AGN-PC-00SCHG } \\
\text { (PubCID: 16064893) }\end{array}$ & non-carcinogen & non- mutagenic & $\begin{array}{l}\text { non- } \\
\text { carcinogen }\end{array}$ & $\begin{array}{c}\text { non- } \\
\text { carcinogen }\end{array}$ & non-carcinogen \\
\hline \multirow{2}{*}{$\begin{array}{l}\text { Sunitinib } \\
\text { similars }\end{array}$} & $\begin{array}{c}\text { Sunitinib simiars } \\
\text { PubCID: } 91384940\end{array}$ & carcinogen & non- mutagenic & $\begin{array}{l}\text { non- } \\
\text { carcinogen }\end{array}$ & carcinogen & non-carcinogen \\
\hline & PubCID: 91066128 & non-carcinogen & non- mutagenic & $\begin{array}{c}\text { non- } \\
\text { carcinogen }\end{array}$ & $\begin{array}{c}\text { non- } \\
\text { carcinogen }\end{array}$ & non-carcinogen \\
\hline
\end{tabular}

Table 6. Predicted ADMET Properties of AGN-PC-0CUK9P

\begin{tabular}{|c|c|c|}
\hline Model & Result & Probability \\
\hline \multicolumn{3}{|l|}{ Absorption } \\
\hline Blood-Brain Barrier & $\mathrm{BBB}+$ & 0.9598 \\
\hline Human Intestinal Absorption & HIA+ & 1 \\
\hline Caco-2 Permeability & $\mathrm{Caco} 2+$ & 0.5477 \\
\hline P-glycoprotein Substrate & Non-substrate & 0.5507 \\
\hline P-glycoprotein Inhibitor & Non-inhibitor & 0.8189 \\
\hline Renal Organic Cation Transporter & Non-inhibitor & 0.5354 \\
\hline \multicolumn{3}{|l|}{ Distribution \& Metabolism } \\
\hline CYP450 2C9 Substrate & Non-substrate & 0.7522 \\
\hline CYP450 2D6 Substrate & Non-substrate & 0.8369 \\
\hline CYP450 3A4 Substrate & Substrate & 0.5263 \\
\hline CYP450 1A2 Inhibitor & Inhibitor & 0.7125 \\
\hline CYP450 2C9 Inhibitor & Non-inhibitor & 0.7599 \\
\hline CYP450 2D6 Inhibitor & Non-inhibitor & 0.8302 \\
\hline CYP450 2C19 Inhibitor & Non-inhibitor & 0.6302 \\
\hline CYP450 3A4 Inhibitor & Non-inhibitor & 0.5371 \\
\hline CYP Inhibitory Promiscuity & High CYP Inhibitory Promiscuity & 0.5669 \\
\hline \multicolumn{3}{|l|}{ Excretion \& Toxicity } \\
\hline Human Ether-a-go-go-Related Gene Inhibition & Weak inhibitor & 0.9018 \\
\hline AMES Toxicity & Non toxic & 0.5321 \\
\hline Acute Oral Toxicity & III & 0.6102 \\
\hline HoneyBee toxicity & Low & 0.7666 \\
\hline
\end{tabular}

to be a better inhibitor amongst the screened compounds in the study. Table 6 shows the complete ADMET profile of AGN-PC-0CUK9P.

Owing to appreciable affinity profile, high kinase activity and non-toxic characteristic of AGN-PC-0CUK9P, it was further mapped for its pharmacophoric properties. As shown in Figure 1
In the inhibitory cavity of RET, the compound is hydrogen bond donor to Phe 735 and acceptor to Gly 736 and Asp 874. There were van der waals contacts with Arg 878, Leu 881, Gly731, Val738, Glu 732, Lys 737 and Phe893 and electrostatic contacts with Asn 879, Asp 892 and 874, Phe735, Gly 736 and 894, Lys 758, Leu 895 and Glu 775. The interactions are further strengthened 


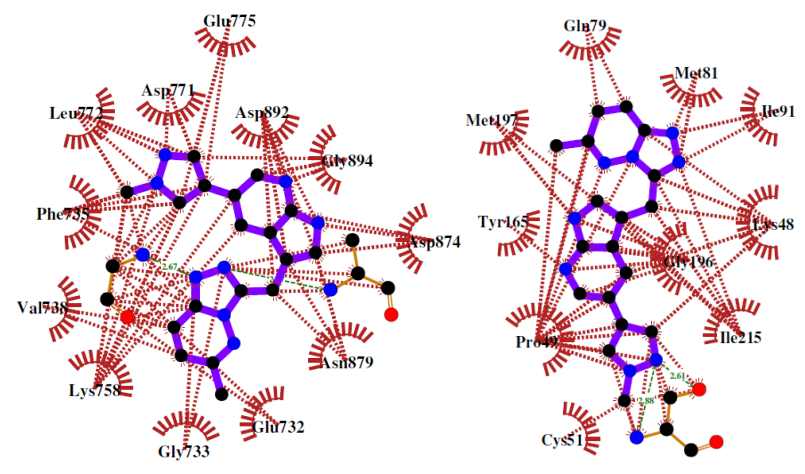

Figure 2. Hydrophobic Contacts of AGN-PC-0CUK9P Interacting the Active site of RET (left) and in the Active site of VEGFR2 (right). The brick red lines represent ligand-residue hydrophobic contacts

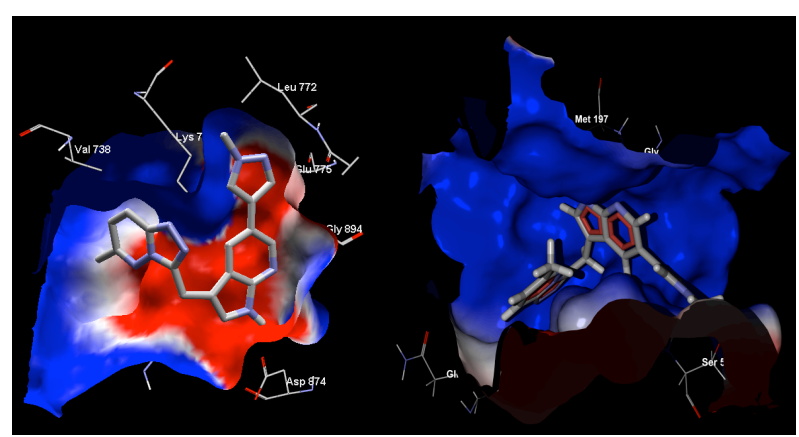

Figure 3. Electrostatic Interaction of AGN-PC0CUK9P Interacting the Active Site of RET (left) and in the Active Site of VEGFR2 (Right). The red and blue color represent electronegative and electropositive surface of the cavity. White is electrically neutral

by pi-pi interactions between the compound and residues like Lys 758.

In the cavity of VEGFR2, the compound establishes $\mathrm{H}$ bonds with Cys 51 and Ile 215. Further in the cavity of VEGFR2 it forms good number of van der waals contacts with Met 197, Ile 91 and 215 Leu 32 and electrostatic interactions with Lys 48, Tyr 165, Gly 196, Cys 51 and Pro 49. pi-pi interactions are also established between Ile91 and Lys 48. Hydrophobic contacts of AGN-PC-0CUK9P in RET and VEGFR2 is shown in Figure 2. Figure 3 shows the electrostatic interactions of AGN-PC-0CUK9P in RET and VEGFR2. It's quite appealing to note that, AGN-PC0CUK9P stabilizes in both electronegative (as seen in RET cavity)and electropositive surfaces (as seen in VEGFR2 cavity). This unique property of this compound in addition explains the better and equivalent binding affinity to both RET and VEGFR2 making it a promiscuous inhibitor.

Dual inhibition of kinase and angiogenesis by targeting RET and VEGFR2 form the rational in the treatment of Medullary Thyroid Cancer (MTC). Although established dual inhibitors have been successful in the inhibiting the kinase and angiogenesis events in MTC, however they fall short due to low inhibitory activity to either RET or VEGFR and often shows extreme side effects . Owing to narrow therapeutic window of established dual inhibitors, by virtual screening procedures we put forth AGN-PC0CUK9P (PubCid: 59320403) as a potential inhibitors which promiscuously targets both RET or VEGFR with similar affinity. In addition AGN-PC-0CUK9P is bestowed with optimal kinase activity, superior pharmacophoric features, better ADMET profiles and least toxicity. In conclusion, AGN-PC-0CUK9P promises to be a potential dual inhibitor and can be further put to pharmacopdynamic and pharmacokinetic studies for further pharmacological evaluation.

\section{Acknowledgements}

The financial support from T.R.R - Research scheme Feb 2012, School of Chemical \& Biotechnology, SASTRA University, Thanjavur, India is gratefully acknowledged.

\section{References}

Bandaru S, Ponnala D, Lakkaraju C, et al (2014). Identification of high affinity non-peptidic small molecule inhibitors of MDM2-p53 interactions through structure-based virtual screening strategies. Asian Pac J Cancer Prev, 16, 37593765 .

Bandaru S, Tiwari G, Akka J, et al (2015). Identification of high affinity bioactive salbutamol conformer directed against mutated (Thr164Ile) beta 2 adrenergic receptor. Cur Top Med Chem, 15, 50-6.

Brierley JD, Tsang R, Simpson WJ, et al. (1996) Medullary thyroid cancer: analyses of survival and prognostic factors and the role of radiation therapy in local control. Thyroid, 6, 305-10.

Brozzo MS, Bjelić S, Kisko K, et al (2012). Thermodynamic and structural description of allosterically regulated VEGFR-2 dimerization. Blood, 119, 1781-8.

Bunone G, Vigneri P, Mariani L, et al (1999). Expression of angiogenesis stimulators and inhibitors in human thyroid tumors and correlation with pathological features. Am J Pathol, 155, 1967-76

Cheng F, Li W,Zhou Y, et al (2012). AdmetSAR: a comprehensive source and free tool for assessment of chemical ADMET properties. J Chem Inf Model, 52, 3099-105.

DeSantis CE, Lin CC, Mariotto AB, et al (2014). Cancer treatment and survivorship statistics, 2014. CA Cancer J Clin, 64, 252-71.

Gilliland FD, Hunt WC, Morris DM, Key CR (1997). Prognostic factors for thyroid carcinoma: a population-based study of 15,698 cases from the Surveillance, Epidemiology and End Results (SEER) program, 1973-1991. Cancer, 79, 564-73.

Hundahl SA, Fleming ID, Fremgen AM, Menck HR (1996). A national cancer database report on 53,856 cases of thyroid carcinoma treated in the U.S., 1985-1995. Cancer, 83, 2638-48.

Jorgensen WL, Maxwell DS \& Tirado-Rives J (1996). Development and testing of the OPLS all-atom force field on conformational energetics and properties of organic liquids. $J$ Am Chem Soc, 118, 11225-36.

Kelotra S, Jain M, Kelotra A., Jain I, et al (2014). An in silico appraisal to identify high affinity anti-apoptotic synthetic tetrapeptide inhibitors targeting the mammalian caspase 3 enzyme. Asian Pac J Cancer Prev, 15, 10137.

Kilfoy BA, Zheng T, Holford TR, et al (2009). International patterns and trends in thyroid cancer incidence, 1973-2002. Cancer Causes Control, 20, 525-31.

Knowles PP, Murray-Rust, et al (2006). Structure and chemical inhibition of the RET tyrosine kinase domain. J Biol Chem, 281, 33577-87. 
Dual Inhibitors Targeting RET and VEGFR2 for Inhibition of Kinase and Angiogenesis in Medullary Thyroid Carcinoma LigPrep, V. (2010). 2.4: Schrodinger. LLC, New York.

Marsh DJ, Learoyd DL, Robinson BG (1995). Medullary thyroid carcinoma: recent advances and managment update. Thyroid, 5, 407-20

Masbi MH, Mohammadiasl J, et al (2014). Characterization of wild-type and mutated RET proto-oncogene associated with familial medullary thyroid cancer. Asian Pac J Cancer Prev, 15, 2027-33.

Maunz A, Gütlein M, Rautenberg M, et al (2013). Lazar: a modular predictive toxicology framework. Front Pharmacol, 4, 38 .

Mitsiades CS, et al (2006). Epidermal growth factor receptor as a therapeutic target in human thyroid carcinoma: mutational and functional analysis. J Clin Endocrinol Metab, 91, 3662-6

Nelder JA \& Mead R (1965). A simplex method for function minimization. Comput $J, 7,308-13$.

Petrangolini G, Cuccuru G, Lanzi C, et al (2006). Apoptotic cell death induction and angiogenesis inhibition in large established medullary thyroid carcinoma xenografts by Ret inhibitor RPI-1. Biochem Pharmacol, 72, 405-14

Rougier P, Parmentier C, Laplanche A, et al (1983). Medullary thyroid carcinoma: prognostic factors and treatment. Int $J$ Radiat Oncol Biol Phys, 9, 161-9

Samaan GA, Schultz PN, Hickey RC (1988). Medullary thyroid carcinoma: prognosis of familial versus sporadic disease and the role of radiotherapy. J Clin Endocrinol Metab, 67, 801-5.

Santoro M and Carlomagno F (2006). Drug Insight: smallmolecule inhibitors of protein kinases in the treatment of thyroid cancer. Nat Clin Pract Endocrinol Metab, 2, 42-52

Schlumberger M, Carlomagno F, et al (2008). New therapeutic approaches to treat medullary thyroid carcinoma. Nat Clin Pract Endocrinol Metab, 4, 22-32.

Thomsen R \& Christensen MH (2006). MolDock: a new technique for high-accuracy molecular docking. $J$ Med Chem, 49, 3315-21.

Yeganeh MZ, Sheikholeslami S, \& Hedayati M. (2015). RET proto oncogene mutation detection and medullary thyroid carcinoma prevention. Asian Pac J Cancer Prev, 16, 2107. 